\title{
Strength Prediction of Corbels Using Strut-and-Tie Model Analysis
}

\author{
Wael Kassem*
}

(Received June 2, 2014, Accepted May 6, 2015, Published online May 30, 2015)

\begin{abstract}
A strut-and-tie based method intended for determining the load-carrying capacity of reinforced concrete (RC) corbels is presented in this paper. In addition to the normal strut-and-tie force equilibrium requirements, the proposed model is based on secant stiffness formulation, incorporating strain compatibility and constitutive laws of cracked RC. The proposed method evaluates the load-carrying capacity as limited by the failure modes associated with nodal crushing, yielding of the longitudinal principal reinforcement, as well as crushing or splitting of the diagonal strut. Load-carrying capacity predictions obtained from the proposed analysis method are in a better agreement with corbel test results of a comprehensive database, comprising 455 test results, compiled from the available literature, than other existing models for corbels. This method is illustrated to provide more accurate estimates of behaviour and capacity than the shear-friction based approach implemented by the ACI 318-11, the strut-and-tie provisions in different codes (American, Australian, Canadian, Eurocode and New Zealand).
\end{abstract}

Keywords: corbels, load-carrying capacity, shear strength, strut-and-tie model.

\section{Introduction}

Reinforced concrete (RC) corbels, defined as short cantilevers jutting out from walls or columns having a shear span-to-depth ratio, $a_{v} / d$, normally less than 1 , are commonly used to support prefabricated beams or floors at building joints, allowing, at the same time, the force transmission to the vertical structural members in precast concrete construction. Corbels are primarily designed to resist vertical loads and horizontal actions owing to restrained shrinkage, thermal deformation and creep of the supported beam and/or breaking of a bridge crane. They are becoming a common feature in building construction with the increasing use of precast concrete. Owing to their geometric proportions, corbels are commonly classified as a discontinuity region (D-region), where the strain distribution over their crosssection depth is nonlinear, even in the elastic stage (MacGregor and Wight 2009), and their strength is predominantly controlled by shear rather than flexure (Yang and Ashour 2012).

The ACI 318-11 code (ACI Committee 318 2011) requires corbels having shear span-to-depth ratio, $a_{v} / d$, less than 2 to be designed using the strut-and-tie method and those with shear-to-span ratio less than 1 to be designed either using strut-and-tie method, or by the closely related traditional ACI design method based on shear-friction approach. However, the shear-friction hypothesis has little correlation with the observed failure phenomenon of concrete crushing in the diagonal strut (Hwang et al. 2000b).

Division of Construction Engineering, College of Engineering at Al-Qunfudah, Umm Al-Qura University, P.O. BOX 288, Al-Qunfudah 21912, Saudi Arabia. *Corresponding Author; E-mail: wakassem@uqu.edu.sa Copyright $($ The Author(s) 2015. This article is published with open access at Springerlink.com
Strut-and-tie models (STM) have been generally recognized as an acceptable rational design approach for D-region members including deep beams and corbels (Schlaich et al. 1987). In addition, most current design codes [ACI Committee 318; Australian code AS 3600 (2009); Canadian code (CSA A23.3-04); Eurocode 2 (2004) and New Zealand code (NZS 3101-1)] have recommended the STM approach as a design tool for RC corbels. However, shear capacity of corbels evaluated from STMs and available formulae and computing procedures showed substantial scatter when compared to experimental results (Hwang et al. 2000b; Ali and White 2001; Russo et al. 2006). A rational design procedure to produce safe and economic corbels is therefore required.

In the current paper, a strut-and-tie based method intended for determining the load-carrying capacity of corbels is presented. In addition to the normal strut-and-tie force equilibrium requirements, the proposed model accounts for strain compatibility and constitutive laws of cracked reinforced concrete, and uses a secant stiffness formulation. A similar approach was used previously to calculate the shear capacity of of squat walls (Hwang et al. 2001), deep beams (Hwang and Lee 2000), beam-column joints (Hwang and Lee 1999, 2000, 2002), dapped-end beams (Lu et al. 2003), and corbels (Hwang et al. 2000a), while using a statically indeterminate truss for modeling the flow of forces and an approximate estimation of members stiffness in evaluating the capacity.

\section{Research Significance}

In the present study, a strut-and-tie based method is developed for calculating the load-carrying capacity of reinforced concrete corbels. The proposed method is based on an 


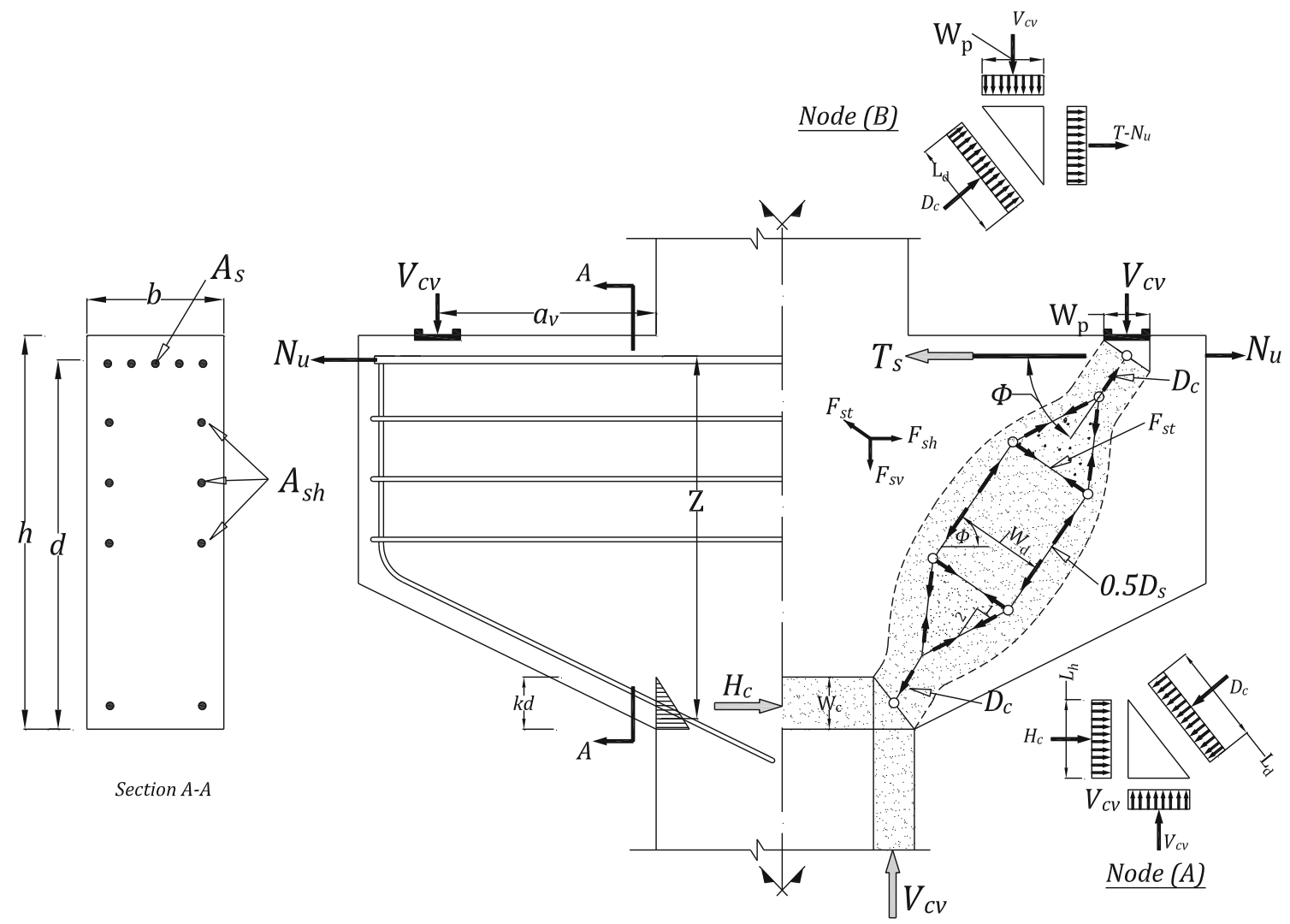

Fig. 1 Geometry and strut-and-tie model with forces acting on corbel.

iterative, secant stiffness formulation and employs constitutive laws for cracked reinforced concrete, while considering strain compatibility. The secant stiffness formulation approach has previously been implemented in nonlinear finite element procedures to predict the nonlinear response of reinforced concrete membrane elements (Vecchio 1989), as well as to estimate the load-carrying capacity of deep beams (Park and Kuchma 2007). The method accounts for the failure modes due to crushing of the nodal compression zone at the top of the diagonal strut, yielding of the longitudinal reinforcement, as well as that of strut crushing or splitting. This method is used successfully to predict the load-carrying capacity of 455 corbels that have been tested experimentally. The findings illustrate that the strut-and-tie model proposed by different code provisions provide conservative and scattered estimates of the strength of corbels, which should be expected since these provisions were developed for the design of all forms of discontinuity regions and not explicitly for corbels.

\section{Compatibility-Based Strut-and-Tie Model Approach for Corbels}

Strut-and-tie modelling is a generalisation of the truss analogy in which a structural continuum is transformed into a discrete truss with compressive forces being resisted by concrete and tensile forces by reinforcement. The method is based on the lower bound theorem of plasticity. Consequently, there are an unlimited number of possible solutions with only some having sufficient ductility for the assumed stress distribution to develop. In the proposed approach, a simple and statically determinate strut-and-tie load path is proposed to model the force transferring within the corbel as shown in Fig. 1. Statically determinant model requires no knowledge of the member stiffness which makes it simple to calculate member forces using simple statics rules. The proposed strut-and tie models assumes that the corbel resists the loads by compressive struts feeding directly into the column, and a tension tie is required to resist the out-ofbalance forces at the loading point.

\section{Equilibrium Conditions}

Figure 1 presents loads acting on a corbel and the proposed force transferring mechanisms in view of the proposed strut-and-tie model. For corbels with short span-to-depth ratios, a large portion of the applied vertical shear force is directly transferred to the supporting columns or walls through inclined strut, with the formation of a full-length horizontal tie to balance the thrust of the inclined struts (Fig. 1). The corbel is loaded by the vertical force $V_{c v}$ applied at the distance $a_{v}$ from the column face and it is assumed that the horizontal outward load, $N_{u}$, is directly applied at the centroid of the principal tensile reinforcement and the effect of shifting is neglected for simplicity (Hwang et al. 2000b). The angle between the compressed diagonal concrete strut and the horizontal direction $\phi$, can be defined as (Russo et al. 2006): 


$$
\phi=\tan ^{-1}\left(\frac{Z}{a_{v}}\right)
$$

where $Z$ is the distance of the lever arm from the centroid of the principal tension steel to the resultant compressive force and $a_{v}$ is the shear span. According to linear bending theory, the lever arm $Z$ of a singly reinforced rectangular section can be estimated as (Hwang et al. 2000a):

$$
Z=d-\frac{k d}{3}
$$

where $d$ is the effective depth of the corbel; $k d$ is the depth of the neutral axis of the cross section; and coefficient $k$ can be defined as (Hwang et al. 2000b):

$$
k=\sqrt{\left(n \rho_{f}\right)^{2}+2 n \rho_{f}}-n \rho_{f}
$$

in which $n$ is the ratio of the elastic moduli of steel and concrete, $n=E_{s} / E_{c}$, and the flexural reinforcement ratio $\rho_{f}$ is assumed to be given by:

$$
\rho_{f}=\frac{A_{s}+\Omega A_{s h}-A_{n}}{b d}
$$

where $A_{n}$ is the cross-sectional area of principal reinforcement used to resist the applied outward load, taken as $A_{n}=N_{u} / f_{y s}$, where $f_{y s}$ is the yielding strength of the principal reinforcement, $A_{s}$ and $A_{s h}$ are the crosssectional areas of the principal tensile reinforcement and horizontal web reinforcement, respectively, and $\Omega$ is an efficiency factor representing the contribution of the web horizontal reinforcement, assumed equal to 0.2 (He et al. 2012). The value of $n$ is obtained by assuming, from ACI 318-11, that $E_{s}=200 \mathrm{GPa}$ and $E_{c}=4700 \sqrt{f_{c}^{\prime}}(\mathrm{MPa})$, it follows that:

$$
n=42.6 / \sqrt{f_{c}^{\prime}} \text {. }
$$

The diagonal strut is assumed to have a bottle-shaped form. That is, it spreads laterally along its length. The lateral spreading of the bottle-shaped strut introduces tensile force transverse to the strut, $F_{s t}$. The tensile force could potentially cause cracking along the length of the strut resulting in a premature failure. Hence, transverse skin reinforcement should be provided in order to control the cracking. The strut compressive force is assumed to spread at a 2:1 slope (longitudinal: transverse direction) as suggested by the ACI 318-11. The considered strutand-tie model leads to the following equilibrium equations:

$$
\begin{aligned}
D_{c} & =\frac{V_{c v}}{\sin \phi} \\
H_{c} & =\frac{V_{c v}}{\tan \phi} \\
F_{s t} & =\frac{V_{c v}}{4 \sin \phi}
\end{aligned}
$$

where $D_{c}, H_{c}$ are the compressive forces in the diagonal and horizontal concrete struts, respectively; and $F_{s t}$ is the bursting tensile force in the tie of the strut-and-tie model. Because the bursting force $F_{s t}$ represents a quarter of the compressive force of the diagonal strut, $D_{c}$, the horizontal and vertical components, $F_{s h}$ and $F_{s v}$ of the tie force can be obtained from equilibrium as follows:

$$
\begin{aligned}
& F_{s h}=\frac{V_{c v}}{4}=\frac{D_{s} \sin \phi}{4} \\
& F_{s v}=\frac{V_{c v}}{4 \tan \phi}=\frac{D_{s} \cos \phi}{4} .
\end{aligned}
$$

\subsection{Secant Stiffness Formulation}

The proposed procedure is based on a compatibility — based iterative, secant stiffness formulation and employs constitutive relations for cracked concrete and reinforcement. The secant stiffness approach was used to calculate the normal strains in the horizontal concrete strut, diagonal concrete strut, horizontal web steel, vertical web steel, and the longitudinal steel tie according to the following equations:

$$
\begin{aligned}
\varepsilon_{d} & =\frac{D_{c}}{\bar{E}_{d} A_{d}} \\
\varepsilon_{c} & =\frac{H_{c}}{\overline{E_{c}} A_{c}} \\
\varepsilon_{h} & =\frac{2 F_{s h}}{\bar{E}_{s h} A_{s h}} \\
\varepsilon_{v} & =\frac{2 F_{s v}}{\bar{E}_{s v} A_{s v}} \\
\varepsilon_{s} & =\frac{T_{s}}{\bar{E}_{s} A_{s}}
\end{aligned}
$$

where $A_{d}, A_{c}$ are the cross-sectional areas of the diagonal and horizontal concrete struts; $A_{s h}, A_{s v}$ and $A_{s}$ are the crosssectional areas of horizontal, vertical and longitudinal steel ties; $\bar{E}_{d}, \bar{E}_{c}, \bar{E}_{s h}, \bar{E}_{s v}$ and $\bar{E}_{s}$, are the corresponding secant moduli. Given compatible stress and strain fields, secant moduli can be defined for the concrete and reinforcement (shown in Fig. 2). Secant moduli can be estimated by (Park and Kuchma 2007):

$$
\begin{aligned}
& \bar{E}_{d}=\frac{\sigma_{2 d}}{\varepsilon_{d}} \\
& \bar{E}_{c}=\frac{\sigma_{2 c}}{\varepsilon_{c}} \\
& \bar{E}_{s h}=\frac{f_{s h}}{\varepsilon_{h}} \\
& \bar{E}_{s v}=\frac{f_{s v}}{\varepsilon_{v}} \\
& \bar{E}_{s}=\frac{f_{s}}{\varepsilon_{s}}
\end{aligned}
$$

where $\sigma_{2 d}, \sigma_{2 c}, f_{s h}, f_{s v}$ and $f_{s}$ are the uniaxial stresses that are obtained from the constitutive relations of each member. 


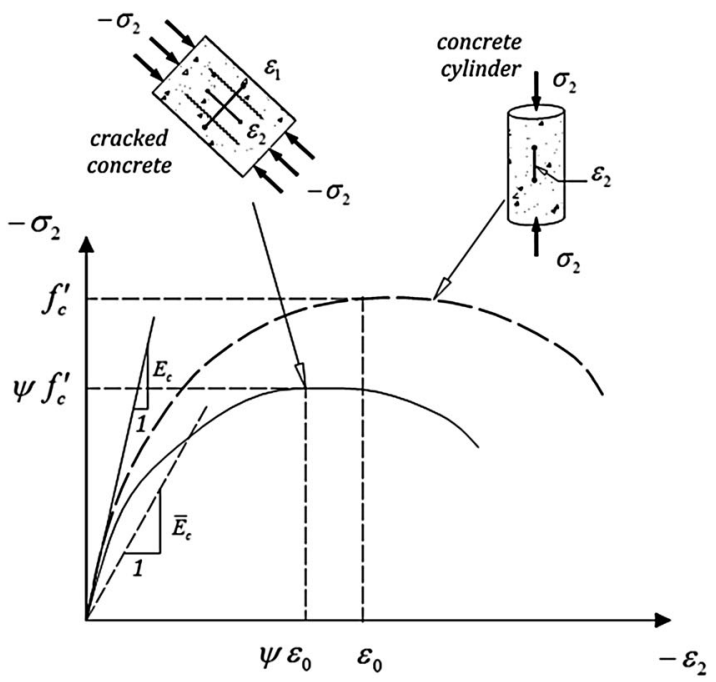

(a)

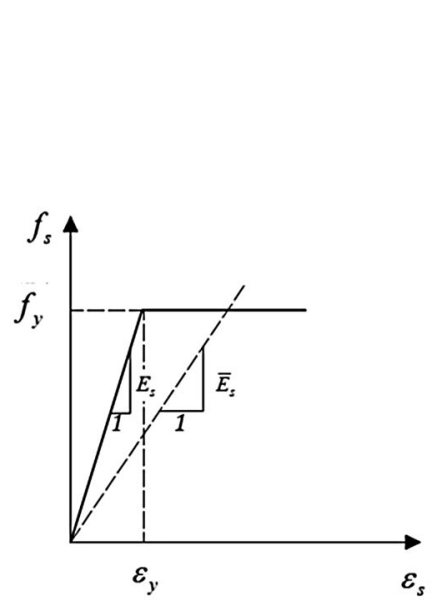

(b)

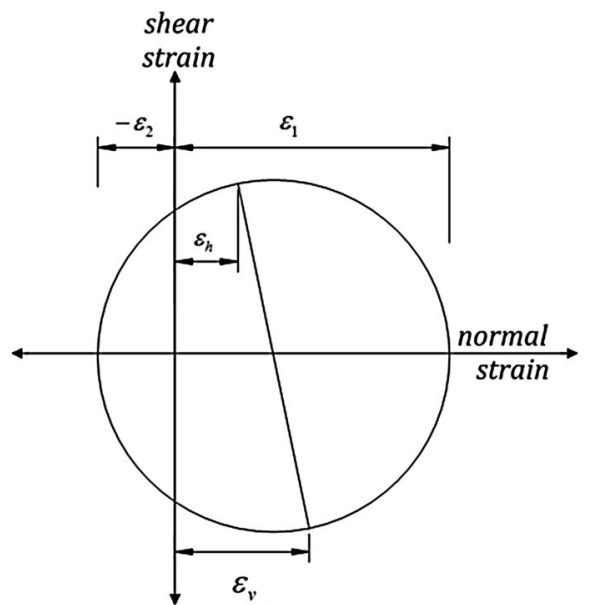

(c)

Fig. 2 Constitutive relations and secant moduli used in analysis procedures for a concrete in compression, b reinforcing steel; and c compatibility conditions for diagonally cracked concrete.

\section{Constitutive Relationships of Concrete and Steel}

\subsection{Softened Concrete in Compression}

Cracked reinforced concrete in compression has been observed to exhibit lower strength and stiffness compared with uniaxially compressed concrete, see Fig. 2a. This phenomenon of strength and stiffness reduction is commonly referred to as compression softening. Applying this softening effect to the strut-and-tie model, it is recognized that the tensile straining perpendicular to the strut will reduce the capacity of the concrete strut to resist compressive stresses. The stress in the concrete is determined from the strains according to the following equations (Vecchio and Collins 1993):

- The ascending branch

$$
\sigma_{2}=\Psi f_{c}^{\prime}\left[2\left(\frac{\varepsilon_{2}}{\Psi \varepsilon_{0}}\right)-\left(\frac{\varepsilon_{2}}{\Psi \varepsilon_{0}}\right)^{2}\right]\left(\frac{\varepsilon_{2}}{\Psi \varepsilon_{0}}\right) \leq 1
$$

- The descending branch

$$
\begin{aligned}
& \sigma_{2}=\Psi f_{c}^{\prime}\left[1-\left(\frac{\left(\varepsilon_{2} / \psi \varepsilon_{0}\right)-1}{4 / \psi-1}\right)^{2}\right]\left(\frac{\varepsilon_{2}}{\Psi} \varepsilon_{0}\right) \geq 1 \quad(21 \mathrm{~b}) \\
& \Psi=\frac{1}{1+k_{c} k_{f}} \quad k_{c}=0.35\left(\frac{-\varepsilon_{1}}{\varepsilon_{2}}-0.28\right)^{0.8} \geq 1.0 \\
& k_{f}=0.1825 \sqrt{f_{c}^{\prime}} \geq 1.0
\end{aligned}
$$

where $\sigma_{2}$ is the average principal stress of concrete in the 2 direction; $\psi$ is the softening coefficient; $f_{c}^{\prime}$ is the compressive strength of a standard concrete cylinder in unit of MPa; $\varepsilon_{2}$ and $\varepsilon_{1}$ are the average principal strains in the 2 and 1 directions, respectively; and $\varepsilon_{0}$ is the concrete cylinder strain corresponding to the cylinder strength $f_{c}^{\prime}$, which can be defined approximately as:

$$
\varepsilon_{0}=0.002+0.001\left(\frac{f_{c}^{\prime}-20}{80}\right) \quad 20 \leq f_{c}^{\prime} \leq 100 \mathrm{MPa} .
$$

\section{Reinforcing Steel}

The stress-strain relationship of steel is assumed to be linear up to yielding, followed by a yield plateau (Fig. 2b). This elastic-perfectly plastic type of stress-strain relationship is represented mathematically by:

$$
\begin{aligned}
& f_{s}=E_{s} \varepsilon_{s} \text { for } \varepsilon_{s} \leq \varepsilon_{y} \\
& f_{s}=f_{y} \text { for } \quad \varepsilon_{s}>\varepsilon_{y}
\end{aligned}
$$

where $E_{s}$ is the elastic modulus of the steel bars; $f_{s}$ and $\varepsilon_{s}$ are the average tensile stress and strain of the reinforcing bars, respectively; and $f_{y}$ and $\varepsilon_{y}$ are the yield stress and strain of the bars, respectively.

\section{Compatibility Condition}

In the proposed approach, the normal tensile strains in the horizontal and vertical web steel, $\varepsilon_{h}$ and $\varepsilon_{v}$ and the principal compressive and tensile strain in concrete strut, $\varepsilon_{2}$ and $\varepsilon_{1}$, have a simple relationship that satisfies the compatibility condition of Mohr's circle (Fig. 2c):

$$
\varepsilon_{h}+\varepsilon_{v}=\varepsilon_{2}+\varepsilon_{1} .
$$

The compatibility equation employed in this paper is the first strain invariant. Equation (24) is used to estimate the value of the principal tensile strain, $\varepsilon_{1}$, which is directly related to the extent of softening of the concrete, as per Eq. (24). Hwang and Lee (2000) pointed out that the used concrete softening model tended to overestimate the softening effect in situations where behaviour was 


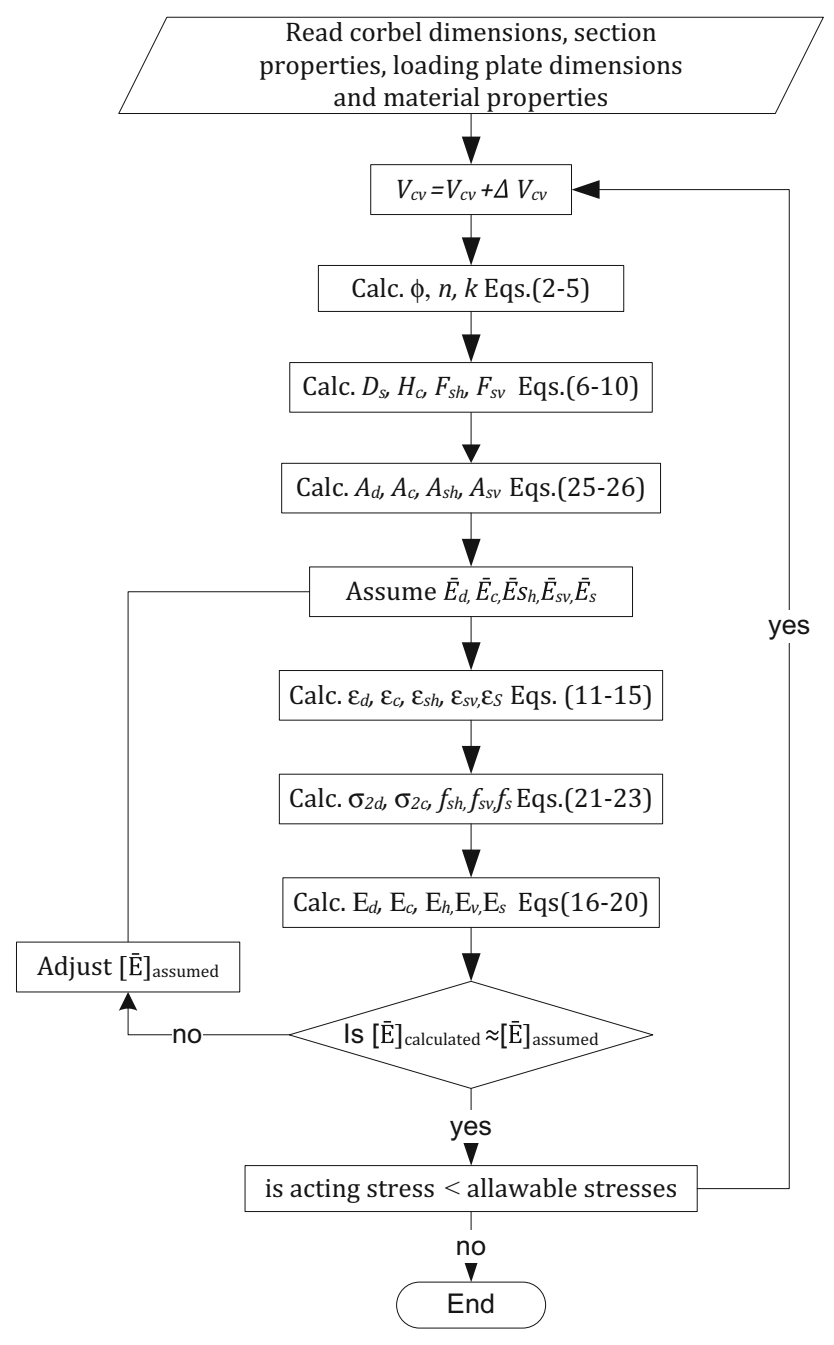

Fig. 3 Flow chart showing solution algorithm. governed by yielding of all reinforcement crossing the crack direction. To guard against this, a limiting value of the principal tensile strain, $\varepsilon_{1}$, was proposed. Thus, the value of tensile strain, $\varepsilon_{h}$, in Eq. (24) is limited by the yielding strain, $\varepsilon_{y h}$, after yielding, or the value of $\varepsilon_{h}$ is set to a yielding strain of 0.002 for the corbels not detailed with a horizontal shear reinforcement. Since all the corbels considered in the current study were not provided with vertical shear reinforcement, the tensile strain $\varepsilon_{v}$ is conservatively taken as 0.002 in Eq. (24).

\section{Effective Depth of Concrete Struts}

Diagonal struts frequently are wider at mid-length than at their ends because strut stresses is greater at mid-length than at the ends of the strut. The curved, dashed outlines of the strut in Fig. 1 represent the effective boundaries of the diagonal strut. In the proposed model, the bottle-shaped strut is idealized as the prismatic struts shown by the straight, solidline boundaries of the struts in Fig. 1. The effective depth of the diagonal strut, $W_{d}$, was assumed equal to (Park and Kuchma 2007):

$$
W_{d}=\frac{a_{v} \sin \phi}{2} k d \cos \phi
$$

where $a_{v} / 2$ should not be less than the loading plate width, $W_{p}$, and $k d$ is the depth of the compression zone at the section. The horizontal bottom strut was assumed to have a uniform prismatic cross section over its length with effective depth $W_{c}$ which is presumed equal to the depth of the neutral axis (He et al. 2012):
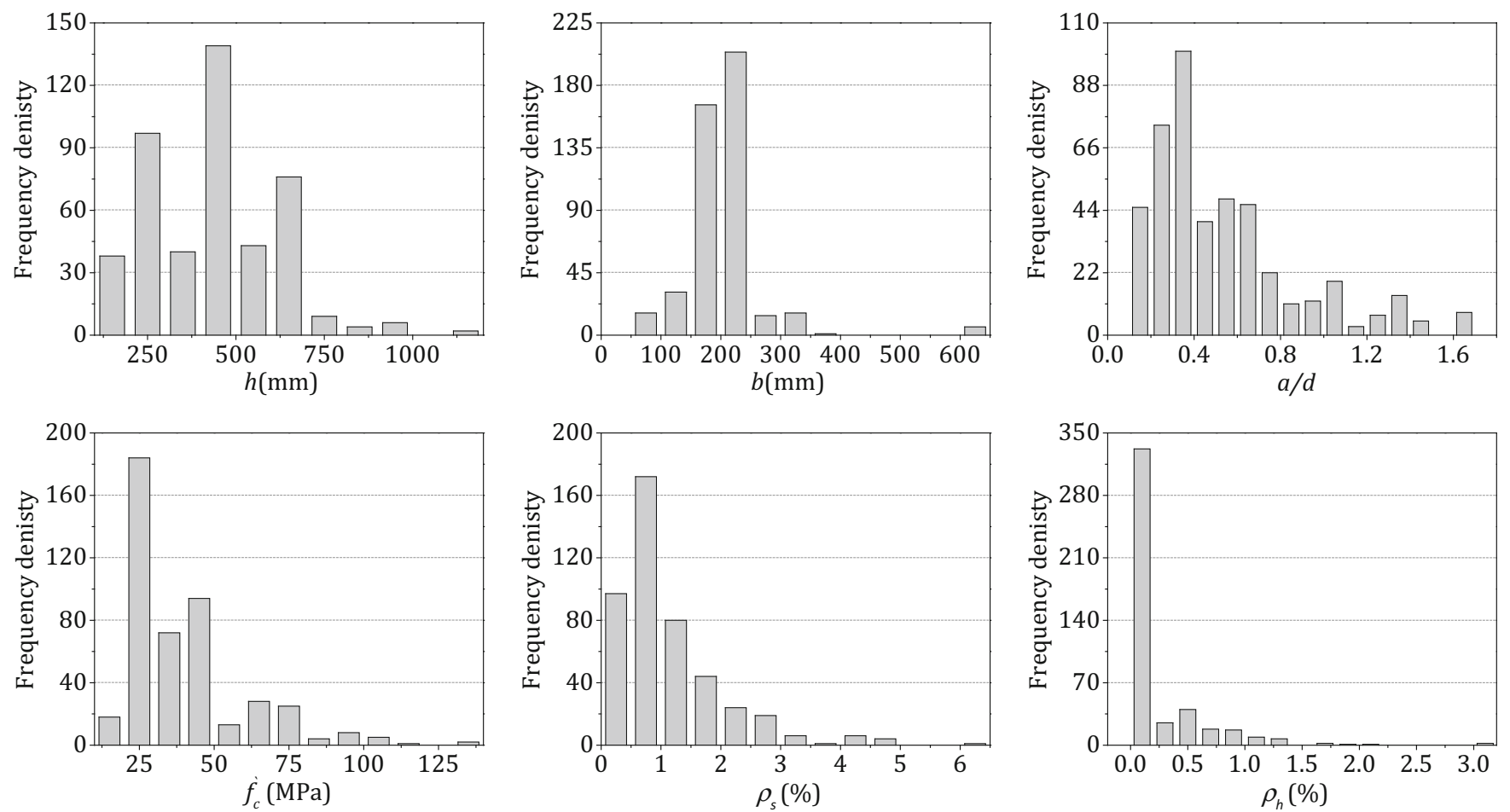

Fig. 4 Histograms of geometric and material properties of 455 reinforced concrete corbels. 


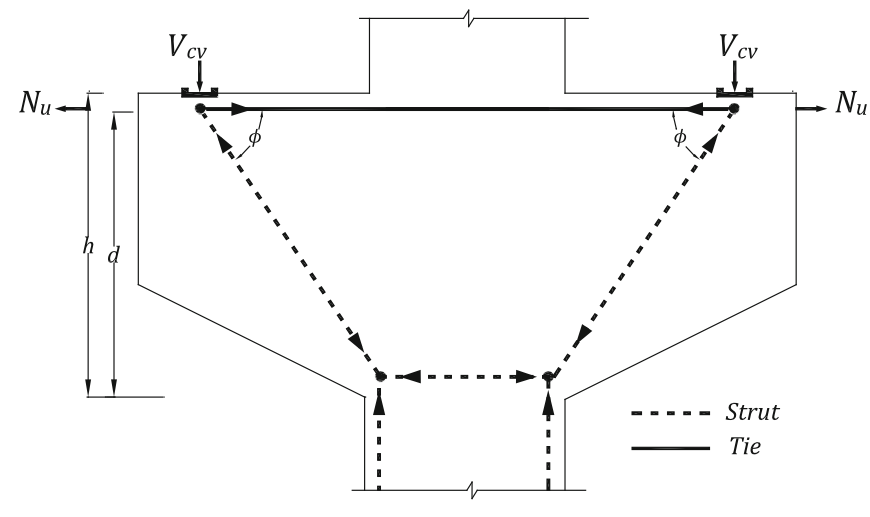

Model (1)

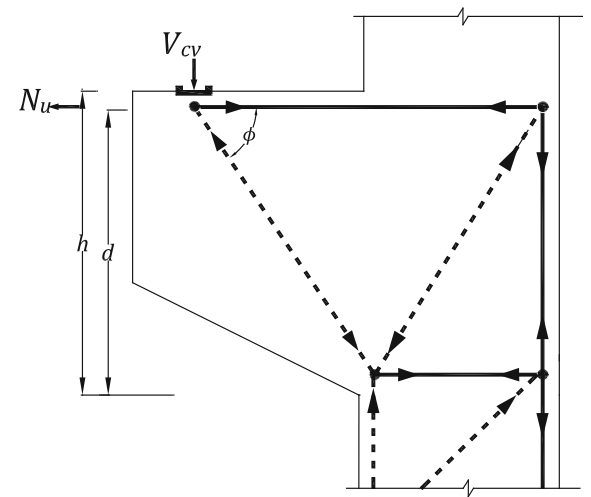

Model (2)

Fig. 5 Selected strut and tie models.

$$
W_{c}=k d
$$

\section{Dimensions of Nodal Zone}

Following the suggestion of Paulay and Priestley (1992), the effective width of the bottom node of the horizontal concrete strut was approximated by the depth of the flexural compression zone of the elastic column as:

$$
L_{h}=\left(0.25+\frac{0.85 N_{u}}{A_{c} f_{c}^{\prime}}\right) h
$$

where $N_{u}$ is the applied horizontal tension load (negative for tension), $A_{c}$ is the gross sectional area of corbel, and $h$ is the corbel overall depth, see Fig. 1. The effective width of the top and bottom nodes in the face of the diagonal concrete strut was taken as:

$$
L_{d}=W_{p} \sin \phi+L_{h} \cos \phi
$$

\section{Proposed Solution Procedures}

The failure modes associated with nodal crushing, yielding of the principal tensile reinforcement, and crushing or splitting of the diagonal strut were used to evaluate the ultimate load-carrying capacity of the corbels. The algorithm in Fig. 3 starts with a selection of the vertical corbel shear force $V_{c v}$ and can be proceeded as outlined in following major steps:

1. According to the member forces $D_{c}, H_{c}, F_{s h}$, and $F_{s v}$, calculated from Eqs. (6) to (10), the values of the strains in concrete struts and steel reinforcements are estimated for the selected $V_{c v}$ using Eqs. (11) through (15). In initiating the analysis, an initial estimate of the material secant stiffness can be made by assuming linear elastic values. Alternatively, the stiffness determined in a previous analysis can be used as the starting values;

2. Using the state of strain in each member, the normal stresses are determined from the stress-strain relations of Eqs. (21a, 21b) through (23a, 23b);
3. The secant moduli for each member are then calculated by Eqs. (16) through (20) using the strain and stresses values calculated in the previous step;

4. If the differences between the secant moduli in step 3 and those assumed in Eqs. (11) through (15) are larger than the specified tolerance, then the assumed secant moduli are considered incorrect and must be revised until convergence;

5. The stresses in the diagonal and horizontal struts, $\sigma_{2 \mathrm{~d}}$ and $\sigma_{2 \mathrm{c}}$, are compared to their capacity. The capacity of the diagonal strut can be estimated from $v_{c v 1}=0.85 \beta_{s} f_{c}^{\prime}$, where $\beta_{\mathrm{s}}=0.6$ as suggested by the ACI 318-11(American Concrete Institute 2011) for bottle-shaped strut with web reinforcements not satisfying the minimum reinforcement requirements, while the capacity of the horizontal strut is taken as $v_{c v 2}=0.85 f_{c}^{\prime}$.

6. The stresses on the on nodes' vertical back face and node-to-strut interface are compared to nominal strengths due to crushing, assumed equal to $V_{c v 4}=$ $0.85 f_{c}^{\prime}$ and $V_{c v s 5}=0.68 f_{c}^{\prime}$ for nodal zones bounded by compressive struts (node A) and nodal zones crossed by tension tie reinforcement in one direction (node B) respectively, refer to Fig. 1;

7. If the acting stress determined in Steps 5 and 6 is less than the allowable stress, iteration continues from Step 1 by increasing the value of $V_{c v}$; and

8. The predicted strength employed in the proposed analysis method is the minimum value of the nominal strengths computed from the different failure modes, which are crushing of the horizontal and diagonal concrete strut, crushing of the compression zone, and yielding of principal tensile reinforcement.

\section{Experimental Verification}

\subsection{Experimental Results Database}

Combining the results of wide-ranging research into a single database provides the ability to examine code provisions as well as develop new models for use in design. 
Table 1 Comparison of experimental and calculated load-carrying capacities of corbels in the database using different methods.

\begin{tabular}{|c|c|c|c|c|c|}
\hline \multicolumn{3}{|c|}{ Strength ratio $\left(v_{\text {test }} / v_{\text {calc }}\right)$} & Avg & Std & $\mathrm{CoV}(\%)$ \\
\hline \multicolumn{3}{|c|}{ Current study } & 1.39 & 0.29 & 21 \\
\hline \multirow{10}{*}{$\begin{array}{c}\text { Strut-and-tie based } \\
\text { models }\end{array}$} & \multirow[t]{2}{*}{ ACI $318-11$} & Model 1 & 1.52 & 1.21 & 79 \\
\hline & & Model 2 & 1.52 & 1.21 & 79 \\
\hline & \multirow[t]{2}{*}{ CSA A23.3-04 } & Model 1 & 1.54 & 1.21 & 78 \\
\hline & & Model 2 & 1.5 & 1.21 & 81 \\
\hline & \multirow[t]{2}{*}{ Eurocode 2} & Model 1 & 1.57 & 1.21 & 77 \\
\hline & & Model 2 & 1.6 & 1.22 & 76 \\
\hline & \multirow[t]{2}{*}{ NZS 3101-1 } & Model 1 & 1.68 & 1.12 & 67 \\
\hline & & Model 2 & 1.68 & 1.12 & 67 \\
\hline & \multirow[t]{2}{*}{ CSA A23.3-04 } & Model 1 & 1.52 & 1.21 & 79 \\
\hline & & Model 2 & 1.52 & 1.21 & 79 \\
\hline \multicolumn{3}{|c|}{ Shear-friction based model } & 1.68 & 0.87 & 52 \\
\hline
\end{tabular}
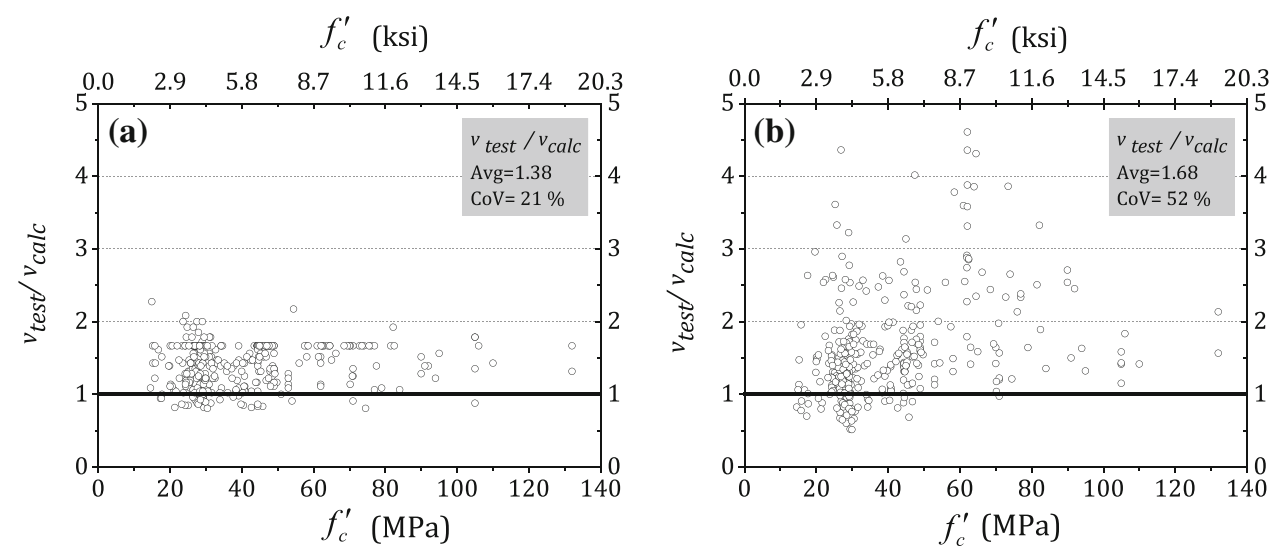

Fig. 6 Effect of concrete strength, $f_{c}$, on shear strength predictions by means of: a proposed strut-and-tie model approach; and b the shear-friction model used by the $\mathrm{ACl} 318-11$ for 357 reinforced concrete corbels.

Aimed at verifying the accuracy of the proposed compatibility-based strut-and-tie method and assessing the performance of code provision that are used in concrete corbels design, a database with relevant information from tests was constructed. The database contains the results of tests of 550 reinforced concrete corbels collected from (in chronological: Abdul-Wahab (1989); Alameer (2004); Bourget et al. (2001); Chakrabarti et al. (1989); Clottey (1977); Fattuhi (1987); Fattuhi (1994); Fattuhi (1990); Foster et al. (1996); Hermansen and Cowan (1974); Kriz and Raths (1965); Lu et al. (2009); (Mattock 1976); Yong and Balaguru (1994) and Yong et al. (1985).

Several possible failure modes of corbels have been identified from past experimental testing, including shearing along the interface between the column and the corbel, yielding of the principal reinforcement and crushing or splitting of the compression strut (Russo et al. 2006). Premature failure modes, such as anchorage failure of principal reinforcement and bearing failure under loading plate, would be avoided by correctly designing the corbel details (ACI Committee 318 2011). The results of corbels that were reported to have failed prematurely and those with insufficient information on the test setup and material properties were excluded from the database, leaving only 455 results in the database. Fig 4 presents summary information associated with different parameters, in the form of histograms, on the $455 \mathrm{RC}$ corbels considered in this study. The test specimens in the database were made of plain and fibrous concrete having a relatively low compressive strength of $14.5 \mathrm{MPa}$ and very high compressive strength of $132 \mathrm{MPa}$. The shear span-to-overall depth ratio of corbels ranged from 0.11 to 1.69. The primary tension reinforcements were anchored using a structural weld to transverse bars, bending to form a horizontal loop, or using headed bars. The main longitudinal reinforcement ratio varied between 0.1 and $6.5 \%$, whereas the horizontal shear reinforcement ratio varied from 0 to $3.05 \%$. All the corbel specimens included in the database had no vertical shear reinforcement. The horizontal load to 

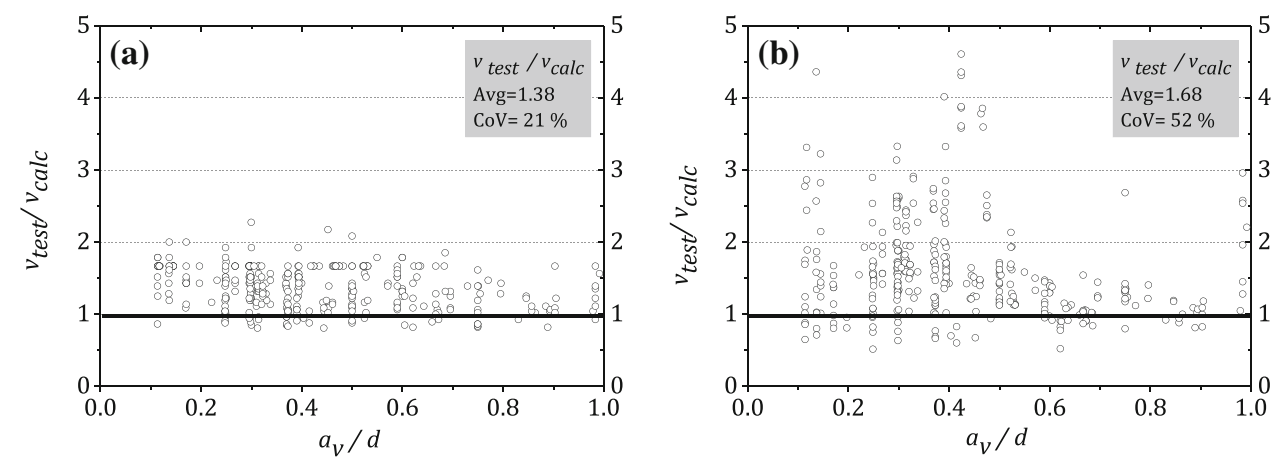

Fig. 7 Effect of shear span-to-depth ratio, $a_{v} / d$, on shear strength predictions by means of: a proposed strut-and-tie model approach; and $\mathbf{b}$ the shear-friction model used by the ACI 318-11 for 357 reinforced concrete corbels.
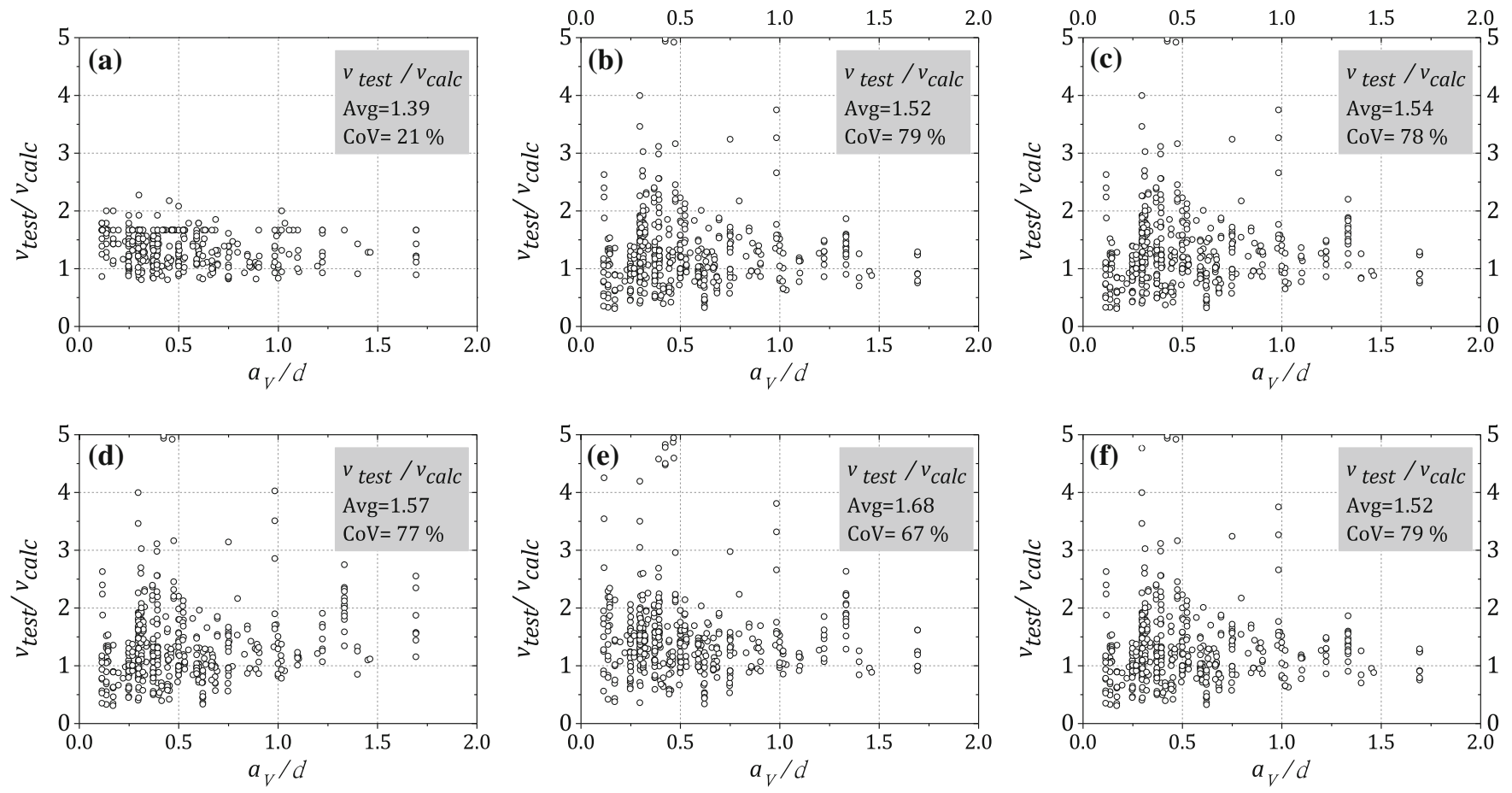

Fig. 8 Variation of ratio of measured-to-calculated strength by means of: a proposed strut-and-tie model approach; b ACI 318-11; c AS 3600; d CSA A23.3-04; e Eurocode 2; and NZS 3101-1 with shear span-to-depth ratio $a_{v} / d$.

yield force of main longitudinal reinforcement ratio ranged from 0 to 1.56. The corbel thickness ranged from 51 to $600 \mathrm{~mm}$ and overall thickness varied between 140 and $1140 \mathrm{~mm}$.

\subsection{Code Provisions and Analytical Models}

Although several methods to compute the strength of RC corbels are adopted in design codes around the world, little is known about the accuracy and conservativeness of design procedures based on different rationales. American (ACI Committee 318 2011), Australian (AS 3600), Canadian (CSA A23.3-04), European (Eurocode 2), and New Zealand (NZS 3101-1) code recommendations include special provisions for corbels design. The main aim of the recommendations is to give practical design rules to avoid brittle shear failure ensuring the development of a well-defined strength mechanism that generally occurs in the formation of a strut-and-tie resistant mechanism. Several other methods are available to estimate the shear capacity of corbels, including empirical equations (Fattuhi 1994), shear-friction approach (Hermansen and Cowan 1974, Mattock 1976), and strut-and-tie models(Solanki and Sabnis 1987; Siao 1994; Hwang et al. 2000b; Russo et al. 2006) including plastic truss models(Campione et al. 2007). The load-carrying capacity of the 455 corbels was calculated using the proposed analysis method, the shear-friction based approach provided by the ACI 318-11(American Concrete Institute 2011) and the strut-and-tie model proposed by different code provisions [ACI Committee 318; Australian code AS 3600; Canadian code (CSA A23.3-04); Eurocode 2 and New Zealand code (NZS 3101-1)].

The shear-friction based approach provided by the ACI 318-11 is valid for corbels made from both normal and high 

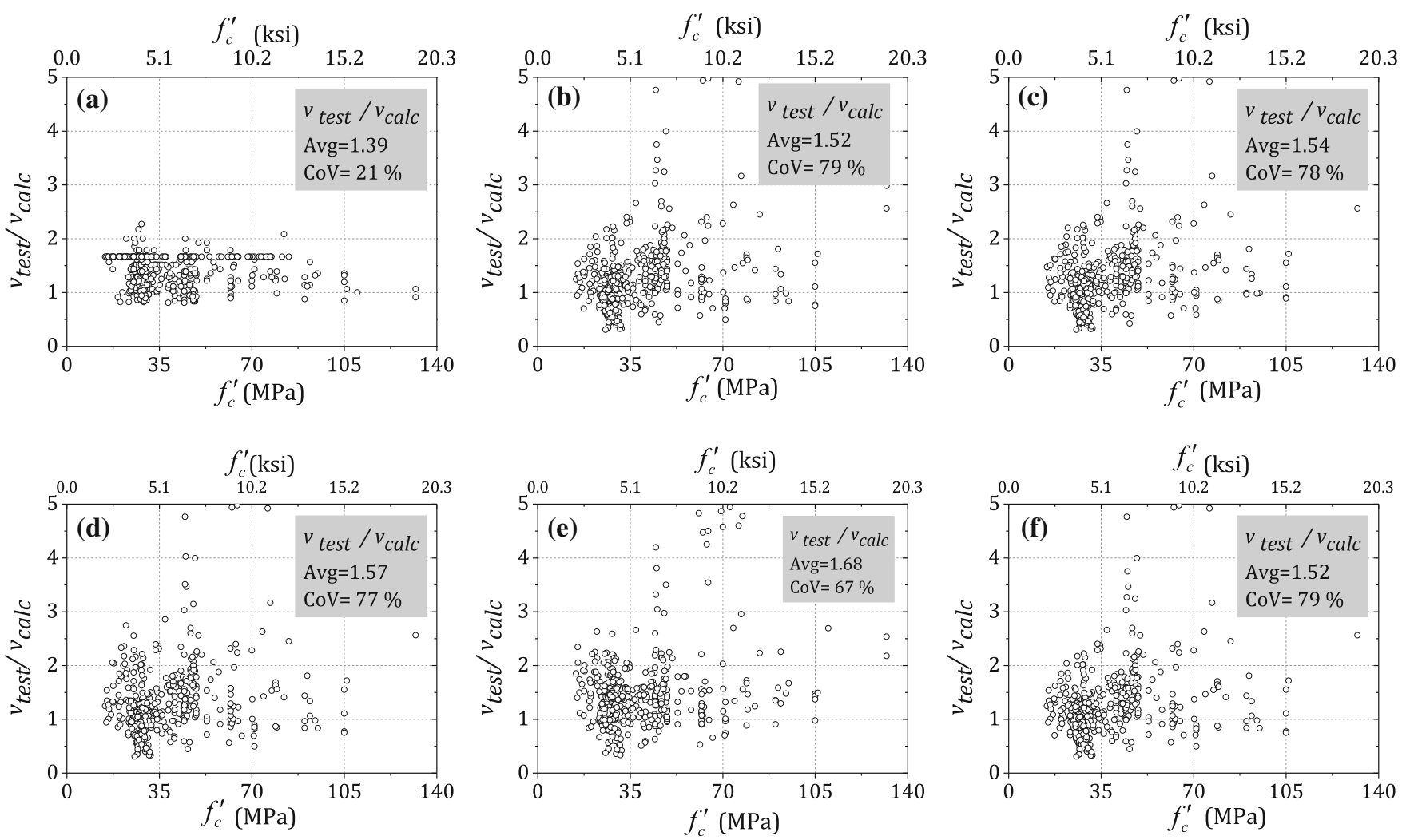

Fig. 9 Variation of ratio of measured-to-calculated strength by means of: a proposed strut-and-tie model approach; $\mathbf{b} \mathrm{ACl} 318-11$; c AS 3600; d CSA A23.3-04; e Eurocode 2; and NZS 3101-1 with concrete strength, $f_{c}$.

strength concrete with span-to-depth ratio less than unity. This procedure refers to two typical modes of failure: the first is the failure mode due to shear constraint occurring at the interface between column and corbel, and which occurs with very small shear-span ratios and reduced percentages of reinforcement. For a shear failure, the shear strength of a corbel is given by:

$$
V_{c v}=\rho_{v f} f_{y s} \mu b d
$$

where $\rho_{v f}=\left(\rho_{s}+\rho_{h}\right)$ is the frictional reinforcement ratio; $f_{y s}$ is the yield strength of the friction reinforcement; $\rho_{s}$ and $\rho_{h}$ is the principal reinforcement ratio and horizontal web reinforcement ratio, respectively; $\mu$ is the coefficient of friction (taken as 1.4 for monolithic construction); and $b$ is the corbel width. The second mode of failure is due to flexural yielding of the principal longitudinal reinforcement, and the carrying capacity can be estimated as:

$$
V_{c v}=\frac{\rho_{s} f_{y} j d}{\left[a_{v}(1+\alpha(h-d))\right]} b d
$$

where $\alpha$ is the horizontal-to-vertical loads ratio; and $j d$ is the lever arm calculated by $j d=d-\frac{\left(A_{s} f_{y s}-N u\right)}{0.88 f_{c}^{\prime} b}$. The corbel strength is taken as the minimum value of Eqs. (29) and (30). Moreover, the code imposes an upper limit on the loadcarrying capacity with a maximum value of $V_{c v}$ shall not exceed the smallest of $0.2 f_{c}^{\prime} b d,\left(3.3+0.08 f_{c}^{\prime}\right)$ $b d$ and $11 b d$.
Several code recommendations (CSA Committee A23.3 2004, NZS 3101 2006) specify the strut-and-tie models for the design of corbels, while only for corbels having shear span-to-depth ratio greater than 1.0, the ACI 318-11 recommends the use of a strut-and-tie model described in ACI 318-11, Appendix A. However, it does not provide detailed guidance on strut-and-tie models for different cases. It is well known that in using the strut-and-tie model, the designer is free to select the form and dimensions of the loadresisting truss to transfer the applied forces to the supports. More than one strut-and-tie model is usually feasible and thus there is no unique design solution as there typically is with the use of the conventional sectional design procedures. The safety of the strut-and tie model approach is highly dependent on the suitability of the assumption in lowerbound plasticity theory that the structure is adequately ductile to allow the load to be supported in the way chosen by the designer.

The experimental results are compared with predictions made on the basis of a simplified strut-and-tie model (STM) accounting for the main tie steel only, a refined strut-and-tie model accounting for the secondary crack-control reinforcement (Reineck 2003). These two models were reported to be very conservative and assume corbels failure are due to yielding of the tie and/or horizontal web reinforcement, thus prevent the assessment of codes provisions (Yang et al. 2012). Instead, two strut-and-tie models for a double-sided corbel and a single corbel projected from a column shown in Fig. 5, are proposed and it is assumed corbel failure is due to 
either crushing of the horizontal and diagonal concrete strut, crushing of the compression zone, or yielding of principal tensile reinforcement, similar to that assumed in the proposed strut-and-tie based method.

\subsection{Comparison of Load-Carrying Capacity}

Very few studies found in the literature on the validity of load-carrying capacity models of RC corbels in code provisions including strut-and-tie models. Table 1 summarizes the average, Avg, standard deviation, SD, and coefficient of variation, $\mathrm{CoV}$, of the ratio between measured and calculated capacities, $v_{\text {test }} / v_{\text {calc }}$, of RC corbels considered, based on the proposed strut-and-tie based method, the shear-friction based approach provided by the ACI 318-11, the strut-and-tie model proposed by five codes of practice examined (ACI 318-11; (c) AS 3600; (d) CSA A23.3-04; (e) Eurocode 2; and NZS 3101-1). The distribution of average strength ratios for the specimens in the database against the concrete strength, $f_{c}^{\prime}$, and shear span-to-depth ratio, $a_{v} / d$, is shown in Figs. 6, 7, 8 9, where Avg and $\mathrm{CoV}$ values are also reported.

For the comparison with the shear-friction based approach provided by the ACI 318-11, only 357 corbels with shear span-to-depth ratio less than unity have been taken into account. Careful examination of the results shows that the shear strength ratios, $v_{\text {test }} / v_{\text {calc }}$, using the shear-friction based approach provides highly conservative and scattered estimates of the strength of corbels over a wide range of concrete strength and shear span-to-depth ratio. The coefficient of variation is quite high, with a value of $52 \%$, thus a low $5 \%$ fractile value is to be expected. Altogether, 51 tests exhibit unconservative estimations, which is remarkably more than the $5 \%$ fractile of 18 tests. Therefore, the results from this new database, which is much larger and more comprehensive than that used to calibrate the shear-friction based approach of ACI 318-11 in the 1980s, are clearly unsafe. In particular, the shear-friction based approach is unconservative in the prediction of the load-carrying capacity for corbels with concrete strength less than $50 \mathrm{MPa}$, (see Fig. 6b). By contrast, the calculated capacities by the proposed strut-and tie based method are both accurate and conservative with low scatter or trends for RC corbels with shear-to-span depth ratios ranging from 0 to 1 (see Fig. 7a).

The selected strut-and-tie models shown in Fig. 5 produce results that are quite similar to each other, refer to Table 1. Figures 7 and 8 present the effect of shear span-to-depth ratio, $a_{v} / d$, and concrete strength, $f_{c}^{\prime}$ on the load-carrying capacity predictions of the strut-and-tie based method and the five codes of practice examined for the double-sided corbel model only, respectively. On the whole, the predictions of the proposed method are very consistent for a broad range of concrete strengths and shear span-to-depth ratio, indicating that Avg, SD and COV are 1.39, 0.29, and $21 \%$, respectively. On the other hand, the overall performances of the five codes of practice examined are very similar, highly conservative and scattered. This conservatism may be attributed to the conservatism in the effective depth of the diagonal strut (Park and Kuchma 2007). They consistently underestimate the load-carrying capacity of corbels with concrete strength greater than $35 \mathrm{MPa}$ and shear span-todepth ratio greater than 0.3 . The largest average of the shear strength ratios, $\left(v_{\text {test }} / v_{\text {calc }}\right)$ of all STM models appear as specified in Eurocode 2. The size of this test database and the use of these five code provisions are enough to obtain valuable insight into the behaviour of $\mathrm{RC}$ corbels from a strutand-tie perspective. Considering the width of the compiled database, the obtained results are considered to be adequately fair to suggest that the proposed strut-and-tie based method provides a reliable and safe means of predicting the loadcarrying capacity of reinforced concrete corbels.

\section{Summary and Conclusions}

A strut-and-tie based method intended for calculating the load-carrying capacity of reinforced concrete corbels has been presented. In addition to the normal strut-and-tie force equilibrium requirements, the proposed model accounts for strain compatibility and stress-strain relationship of cracked reinforced concrete, and uses a secant stiffness formulation. Based on the available test results in the literature and their comparison with the proposed model and the shear-friction based approach provided by the ACI 318 formulas as well as the strut-and-tie provisions in the American, Canadian, New Zealand, Eurocode and Australian codes., the following conclusions may be drawn:

1. The calculated load-carrying capacities by the proposed method were both accurate and conservative with limited scatter or trends for reinforced concrete corbels with shear span-to-depth ratios ranging from 0.1 to 2 and made from normal or fibrous concrete.

2. The shear-friction based approach provided by the American code is highly conservative and scattered estimates of the strength of corbels over a wide range. By contrast, the calculated capacities by the proposed strut-and tie based method are both accurate and conservative with low scatter or trends for RC corbels with shear-to-span depth ratios ranging from 0 to 1 .

3. The predictions by the proposed strut-and-tie based method are adequately conservative and accurate to conclude that it provides a safe and reliable means of calculating the load-carrying capacity of concrete corbels.

4. Based on the conclusions drawn from this research, the proposed strut-and-tie should be adopted in future adjustments to code provisions and in the development of design guidelines for all types of D-regions in structural concrete. Furthermore, both experimental and mathematical studies are still needed to investigate the applicability and limitations of the proposed strut-andtie method when applied to a wide range of D-regions.

\section{Acknowledgment}

The Author would like to thank Prof. Keun-Hyeok Yang, Kyonggi University, South Korea for providing some 
information on tests of corbels and assistance in populating the corbels database.

\section{Open Access}

This article is distributed under the terms of the Creative Commons Attribution 4.0 International License (http:// creativecommons.org/licenses/by/4.0/), which permits unrestricted use, distribution, and reproduction in any medium, provided you give appropriate credit to the original author(s) and the source, provide a link to the Creative Commons license, and indicate if changes were made.

\section{References}

Abdul-Wahab, H. M. (1989). Strength of reinforced concrete corbels with fibers. ACI Structural Journal, 86(1), 60-66.

Alameer, M. (2004). Effects of fibres and headed bars on the response of concrete corbels. M SC thesis, Department of Civil Engineering and Applied Mechanics, McGill University, Montreal, Canada.

Ali, M., \& White, R. (2001). Consideration of compression stress bulging and strut degradation in truss modeling of ductile and brittle corbels. Engineering Structures, 23(3), 240-249.

American Concrete Institute. (2011). Building Code Requirements for Structural Concrete (ACI 318-11) and Commentary (ACI 318R-11). Farmington Hills, MI: ACI.

Australian code AS 3600. (2009). Australian Standard for Concrete Structures (p. 213). North Sydney, Australia: Standards Australia.

Bourget, M., Delmas, Y., \& Toutlememonde, F. (2001). Experimental study of the behaviour of reinforced highstrength concrete short corbels. Materials and Structures, 34(3), 155-162.

British Standards Institution. (2004). Eurocode 2: Design of concrete structures-Part 1-1: General rules and rules for buildings. London, UK: British Standards Institution.

Campione, G., La Mendola, L., \& Mangiavillano, M. L. (2007). Steel fiber-reinforced concrete corbels: Experimental behavior and shear strength prediction. ACI Structural Journal, 104(5), 570-579.

Chakrabarti, P. R., Farahi, D. J., \& Kashou, S. I. (1989). Reinforced and precompressed concrete corbels-an experimental study. ACI Structural Journal, 86(4), 132-142.

Clottey, C. (1977). Performance of lightweight concrete corbels subjected to static and repeated loads. $\mathrm{PhD}$ thesis, Oklahoma State University, Ann Arbor, MI, pp. 127-127.

CSA Committee A23.3. (2004). Design of concrete structures. Mississauga, Canada: Canadian Standard Association 232.

Fattuhi, N. (1987). SFRC corbel tests. ACI Structural Journal, 84(2), 119-123.

Fattuhi, N. (1990). Strength of SFRC corbels subjected to vertical load. Journal of Structural Engineering, 116(3), 701-718.
Fattuhi, N. (1994). Reinforced corbels made with plain and fibrous concretes. ACI Structural Journal, 91(5), 530-536.

Foster, S. J., Powell, R. E., \& Selim, H. S. (1996). Performance of high-strength concrete corbels. ACI Structural Journal, 93(5), 555-563.

He, Z.-Q., Liu, Z., \& Ma, Z. J. (2012). Investigation of loadtransfer mechanisms in deep beams and corbels. $A C I$ Structural Journal, 109(4), 467-476.

Hermansen, B. R., \& Cowan, J. (1974). Modified shear-friction theory for bracket design. ACI Journal Proceedings, 71(2), 55-60.

Hwang, S.-J., Fang, W.-H., Lee, H.-J., \& Yu, H.-W. (2001). Analytical model for predicting shear strength of squat walls. Journal of Structutral Engineering, ASCE, 127(1), 43-50.

Hwang, S.-J., \& Lee, H.-J. (1999). Analytical model for predicting shear strengths of exterior reinforced concrete beam-column joints for seismic resistance. ACI Structural Journal, 96(5), 846-857.

Hwang, S.-J., \& Lee, H.-J. (2000). Analytical model for predicting shear strengths of interior reinforced concrete beamcolumn joints for seismic resistance. ACI Structural Journal, 97(1), 35-44.

Hwang, S.-J., \& Lee, H.-J. (2002). Strength prediction for discontinuity regions by softened strut-and-tie model. Journal of Structural Engineering, 128(12), 1519-1526.

Hwang, S.-J., Lu, W.-Y., \& Lee, H.-J. (2000a). Shear strength prediction for deep beams. ACI Structural Journal, 97(3), 367-376.

Hwang, S.-J., Lu, W.-Y., \& Lee, H.-J. (2000b). Shear strength prediction for reinforced concrete corbels. ACI Structural Journal, 97(4), 543-552.

Kriz, L. B., \& Raths, C. H. (1965). Connections in precast concrete structures-Strength of corbels. PCI Journal, 10(1), 16-61.

Lu, W.-Y., Lin, I.-J., \& Hwang, S.-J. (2009). Shear strength of reinforced concrete corbels. Magazine of Concrete Research, 61(10), 807-813.

Lu, W. Y., Lin, I. J., Hwang, S. J., \& Lin, Y. H. (2003). Shear strength of high-strength concrete dapped-end beams. Journal of the Chinese Institute of Engineers, 26(5), 671-680.

MacGregor, J., \& Wight, J. (2009). Reinforced concrete: Mechanics and design. Singapore: Prentice Hall and Pearson Education South Asia.

Mattock, A. H. (1976). Design proposals for reinforced concrete corbels. PCI Journal, 21(3), 18-42.

NZS 3101. (2006). Part 1: Code of practice for the design of concrete structures and Part 2: Commentary on the design of concrete structures. Wellington, New Zealand: Standards Association of New Zealand.

Park, J., \& Kuchma, D. (2007). Strut-and-tie model analysis for strength prediction of deep beams. ACI Structural Journal, 104(6), 657-666.

Paulay, T., \& Priestley, M. (1992). Seismic design of reinforced concrete and masonry buildings. New York, NY: Wiley.

Reineck, K. (2003). Examples for the design of structural concrete with strut-and-tie models. ACI International, SP$208,128-141$. 
Russo, G., Venir, R., Pauletta, M., \& Somma, G. (2006). Reinforced concrete corbels-shear strength model and design formula. ACI Materials Journal, 103(1), 3-10.

Schlaich, J., Schäfer, K., \& Jennewein, M. (1987). Toward a consistent design of structural concrete. PCI Journal, 32(3), 74-150.

Siao, W. B. (1994). Shear strength of short reinforced concrete walls, corbels, and deep beams. ACI Structural Journal, 91(2), 123-132.

Solanki, H., \& Sabnis, G. M. (1987). Reinforced concrete corbels-simplified. ACI Structural Journal, 84(5), 428-432.

Vecchio, F. J. (1989). Nonlinear finite element analysis of reinforced concrete membranes. ACI Structural Journal, 86(1), 26-35.

Vecchio, F. J., \& Collins, M. P. (1993). Compression response of cracked reinforced concrete. Journal of Structural Engineering, 119(12), 3590-3610.
Yang, K.-H., \& Ashour, A. F. (2012). Shear capacity of reinforced concrete corbels using mechanism analysis. Proceedings of the ICE-Structures and Buildings, 165(3), $111-125$.

Yang, J., Lee, J., Yoon, Y., Cook, W., \& Mitchell, D. (2012). Influence of steel fibers and headed bars on the serviceability of high-strength concrete corbels. Journal of Structural Engineering, 138(1), 123-129.

Yong, Y., \& Balaguru, P. (1994). Behavior of reinforced highstrength-concrete corbels. Journal of Structural Engineering, 120(4), 1182-1201.

Yong, Y., McCloskey, D. H., \& Nawy, E. G. (1985). Reinforced corbels of high-strength concrete. London, UK: ACI Special Publication. 87. 